\title{
RESEARCH PAPER \\ THE EXPRESSION OF SLAMF7 LEVELS IN MALIGNANT B CELLS: A NOVEL THERAPEUTIC PATHWAY FOR PATIENTS WITH CLL
}

\author{
D. N. Ofosu ${ }^{1,2^{*}}$, C. Opoku-Okrah ${ }^{2}$, B. Nkum ${ }^{3}$ and J. Murphy ${ }^{1}$ \\ ${ }^{1}$ Department of Biomedical Science, School of Science and Technology, University of Westminster, \\ London, \\ ${ }^{2}$ Department of Medical Laboratory Technology, Faculty of Allied Health Sciences, College of \\ Health Sciences, KNUST, Kumasi \\ ${ }^{3}$ School of Medical Sciences, College of Health Sciences, KNUST, Kumasi \\ *Corresponding author: ntiamoah13@yahoo.com
}

\begin{abstract}
Signalling lymphocyte activation molecule (SLAM) F7 is found on the surface of some immune cells including B-lymphocytes. Its activation leads to the proliferation or differentiation of immune cells. The objectives of the study were to measure SLAMF7 expression levels on B-CLL cells, and to upregulate the expression of SLAMF7 with phorbol myristate acetate (PMA) and Bryostatin. The levels of expression of SLAMF7 receptors of B-CLL cells from patients were measured; using immunofluorescence, flow cytometry, confocal microscopy and reverse transcriptase polymerase chain reaction (RT-PCR). The effects of treatments with PMA and Bryostatin were determined from different patients. Different levels of SLAMF7 expression were found to be associated with B-CLL cells from different patients. PMA treatment of B-CLL cells showed more positive SLAMF7 staining with the majority of the extracted B-CLL cell cases, while less positive results were associated with Bryostatin treatment. The study has shown that both PMA and Bryostatin could upregulate SLAMF7. Successful modulation of SLAMF7 expression may provide a novel target for the treatment of patients with CLL.
\end{abstract}

Keywords: SLAMF7, RT PCR, Elotuzumab, Bryostatin, PMA

\section{INTRODUCTION}

Signalling lymphocyte activation molecule (SLAM) F7, is among the members of SLAM family of receptors found on the surface of some specific immune cells that regulate several functions of different immune cell types (Murphy et al., 2002; Bouchon et al., 2001; Veillett and Latour, 2003; Lee et al., 2007; Stark and Watzl, 2006). According to the Hugo
Gene Nomenclature (2012), SLAMF7 contains one immunoglobulin-like C2-type domain. Expression of SLAMF7 can be found in lymph nodes, bone marrow, stomach, trachea, spleen, lungs, appendix, small intestine and peripheral leucocytes (Calpe et al., 2008).

Activation of SLAMF7 receptor leads to stimulation of the signal transduction pathway, 
which results in the proliferation or differentiation of the immune cell (Cambier et al., 1994; Jiang et al., 2005). Currently, a monoclonal antibody, Elotuzumab used in the treatment of multiple myeloma is known to target SLAMF7 (Richardson et. al., 2011) and has been successfully targeted with Elotuzumab, a novel drug for the treatment of CLL (Murphy et al., 2002).

Protein kinase $\mathrm{C}$ (PKC) activators like phorbol esters and Bryostatins affect the signal transduction pathway, which has enormous effect on a variety of biological responses, which include proliferation and differentiation (Cambier and Ransom, 1987; King, 1988; Isakov et al., 1986; Muhie et al., 2013). Bryostatins are antipromoters of tumour cells (Hennings et al., 1990); hence they are more significant in clinical trials, than phorbol esters like phorbol myristate acetate (PMA), which are carcinogenic (Nishimoto et al., 2013; Hennings et al., 1987). The optimal concentration for Bryostatin modulation of SLAMF7 is suggested to be 10nM (Drexler et al., 1989), which has been corroborated by Murphy et al. (2002). This study aims to upregulate the expression of SLAMF7 receptors with protein kinase C (PKC) activators (Bryostatin and PMA). Successful modulation of SLAMF7 expression may provide a novel target for the treatment of patients with chronic lymphocytic leukaemia.

\section{MATERIALS AND METHODS \\ Sample population}

Between July 2013 and August 2013, consecutive samples of CLL patients were selected for the study. Blood samples were collected from the CLL patients attending the oncology clinic (Department of Haematology, UCL Cancer Research Institute) at the University College of London Hospital, London, UK. They were analysed at the University of Westminster Immunology Laboratory. The samples collected were from twenty-two patients with the malignancy who were from different ethnic backgrounds. Twelve (12) of them who had significant amount of white cell counts $\left(5 \times 10^{5}\right.$ cells $\left./ \mathrm{ml}\right)$ were subsequently enrolled into the study.
Stored frozen multiple myeloma cells and some B-CLL cells were obtained from University of Westminster (extracted and stored from previous studies).

\section{LABORATORY METHODS}

Whole blood samples collected by venepuncture were processed immediately by extracting the white blood cells (WBC). $8 \mathrm{mls}$ of blood sample was added to equal volume of RPMI 1640 medium with L-glutamine (SigmaAldrich Company Ltd, UK) and mixed. $15 \mathrm{mls}$ of histopaque reagent (Sigma-Aldrich Company Ltd, UK) was added to $10 \mathrm{mls}$ of the blood: RPMI mixture previously constituted. The addition was done carefully drop by drop unto the surface of the histopaque, taking care that it settled on the top of the histopaque. The new mixture was centrifuged at $2500 \mathrm{rpm}$ at $22^{\circ} \mathrm{C}$ for 30 minutes. This was to allow all other cells to go through the semi-solidified histopaque, while leaving the white cells on top. Approximately $3 \mathrm{mls}$ of B-CLL cells suspended on the surface of the histopaque was carefully transferred into a universal tube, and RPMI 1640 medium was added. Further centrifugation at $1500 \mathrm{rpm}$ at $4^{\circ} \mathrm{C}$ and for 5 minutes was done to obtain a pure sample with minimal contamination from other cells. The supernatant was decanted and white cell pellets (B-CLL cells) were resuspended in the remaining medium and counted in the Neubauer chamber. Subsequently RNeasy Minikit (Qiagen, UK) was used to isolate $1 \mu \mathrm{g}$ of its ribonucleic acid (RNA) following the manufacturer's protocol.

Samples that could not be processed immediately were stored in liquid nitrogen. A minimum of $5 \times 10^{5}$ cells $/ \mathrm{ml}$ was required for selection and running in each experiment.

\section{Cell culture testing}

A concentration of $0.5 \times 10^{6}$ B-CLL cells was cultured using RPMI-1640 as medium in a sixwell culture plate (Thermo Fisher Scientific, Sigma-Aldrich). Duplicates of test (wells with PMA or Bryostatin treatment) and control (wells without PMA or Bryostatin treatment) 
were prepared following standard protocol, as described by Murphy et al. (2002). Cells of test samples were stimulated with a $30 \mathrm{nM}$ concentration of PMA (Sigma, Poole, Dorset), or a 10 nM Bryostatin (Sigma, Poole, Dorset). Additionally, a dose-response testing, using $0 \mathrm{nM}$, $10 \mathrm{nM}, 20 \mathrm{nM}$ and $40 \mathrm{nM}$ of Bryostatin was done, followed by 24 hours incubation at $37^{\circ} \mathrm{C}$ with antibiotics (L-glutamine and penicillin/ streptomycin) and $10 \% \mathrm{v} / \mathrm{v}$ foetal bovine serum (Sigma-Aldrich, UK). The result showed successful proliferation and differentiation of the B -CLL cells after treatment with Bryostatin. The dose-response study also showed that the optimal dose for proliferation and differentiation of the B-CLL cells using Bryostatin was $10 \mathrm{nM}$.

\section{Immunofluorescence testing}

Cells obtained from the culture study were resuspended, washed twice with phosphate buffer saline and $0.1 \%$ bovine serum antibody, (staining solution mixture) and transferred into a $5 \mathrm{ml}$ falcon tube following the protocol by Murphy et al. (2002). $5 \mu$ l of Anti-SLAMF7 purified mouse monoclonal IgG2a (R\&D systems, Minneapolis, MN) was added to the suspended pellets. The Anti-SLAMF7 purified mouse monoclonal IgG2a then binds with SLAMF7 receptors (antigen) forming antigenantibody complex on the B-CLL cells, if present, and served as positive control, while Ig$\mathrm{GA}_{2}$ which does not contain Anti-SLAMF7 antibody was added in a second falcon tube as negative control, before incubating at $4^{\circ} \mathrm{C}$ on ice. After washing with the staining solution mixture the cells were stained with Fluorescein Isothiocyanate (FITC) labelled polyclonal goat anti mouse IgG (Dako Company, Denmark).

\section{Flow cytometry assay}

The cells obtained from the immunofluorescence testing were subjected to flow cytometry testing to determine the level of SLAMF7 receptors on the B-CLL cells following standard protocol provided by Dako Company. The results were recorded as mean fluorescence intensity (MFI) and percentage positive of SLAMF7 receptors on the cell surface. Control samples (without Anti-SLAMF7 treatment) showed low expression levels while positive test samples (with Anti-SLAMF7 IgG2a) showed positive results. Flow cytometry was also used to determine the optimal dose response using Bryostatin treatment.

\section{Confocal microscopy}

The levels of expression/fluorescence of the SLAMF7 receptors were determined on the BCLL cell prior to the treatment and after treatment of the cells. This was visualised using a confocal microscope to detect the dye fluorescence on the cell surfaces. The observation was done in the dark room (to avoid sunlight interacting with the dye) using the Leica TCS SP2 confocal microscopy system (Leica Microsystems, Milton Kynes, and UK).

\section{Reverse transcriptase polymerase chain re- action (RT-PCR)}

This was performed to identify the presence and level of expressing mRNA of SLAMF7 receptors on B-CLL cells before and after upregulation. This involved RNA extraction using RNeasy Minikit (Qiagen Sample and Assay Technologies, UK), in accordance with the manufacturer's protocol. The pure sample of the white cells was harvested by adding buffer RLT $(350 \mu \mathrm{L})$ from the Qiagen kit. Samples were then passed through several washes with Qiagen reagent buffers, which were placed in a RNeasy spin column and were centrifuged at $\geq 8000 \mathrm{x}$ g for $15 \mathrm{~s}$. The resulting total RNA was extracted into approximately $50 \mu \mathrm{L}$ of RNase free water and measured spectrophotometrically using the Nanodrop automated machine (Thermo Scientific, USA) (at an absorbance of $260 \mathrm{~nm}$ and $280 \mathrm{~nm}$ ) to determine the right molecular weight for RT-PCR. The optimal RNA ratio read by the Nanodrop Spectrophometer for the samples was 1:1.9 - 2.1. This indicates the purity of the sample being analysed, because a lower ratio than 1.9 suggest the presence of contaminants, such as proteins that absorb UV light. An amount of RNA $(1 \mu \mathrm{g})$ was measured and was reverse-transcribed to produce cDNA. Random primers and oligo-dT, 
using the GO TAG SYBR green PCR kit (Promega Corporation, UK) with Biometra PCR machine (Thistle Scientific, UK). The forward primer 5'-GCCAAT GAGTCC CATAAT-3' and the reverse primer 5'GTATTT GCTGGA TCTTCC-3' (Life Technologies Invitrogen Corporation, UK) were used to amplify the cDNA material. A $2 \%$ agarose gel electrophoresis was run, using TRIS/ Borate/EDTA (TBE) at 100 volts for $40 \mathrm{~min}$ utes. The molecular weight marker of $100 \mathrm{bp}$ was used (Promega Corporation, Madison, USA) as a control ladder for the amplified cDNA product. Ethidium bromide was used in staining the DNA to enable the products to be visualised using an ultra violet (UV) Trans Illuminator Imaging System (UVItec Limited, Cambridge, UK).

\section{Ethical Approval}

Ethical clearance was obtained from two bodies; the Committee on Human Research Publication and Ethics, School of Life Sciences, University of Westminster and Department of Cancer Studies, UCL Hospital (REC reference number, 09/H07146).

\section{RESULTS}

Establishing the optimal dose response of
Bryostatin using cell culture and flow cytometry studies

Initial studies undertaken to establish the optimal concentration of Bryostatin for upregulation of SLAMF7 showed that Bryostatin treatment was effective at an optimal concentration of $10 \mathrm{nM}$. (Table 1).

The effect of Bryostatin on the receptors of SLAMF7 modulation on B-CLL cells showed that $10 \mathrm{nM}$ produced the highest peak of SLAMF7 expression, but the expression declined after the concentrations were subsequently increased to $20 \mathrm{nM}$ and $40 \mathrm{nM}$. This trend was observed with all cases of B-CLL patients selected for dose-response testing.

\section{Cell culture and morphological features of $B$ -CLL cells}

It was observed that culture plates treated with PMA had the most cells aggregating or forming clusters that led to clumps in certain areas on the plates (Fig 1). Untreated medium had fairly evenly distributed cells on the plate with little evidence of clumping (Fig 1A).

Bryostatin treatment also showed some clump formation (Fig 1C), even though they were in fewer areas, compared to clumping occurring

Table 1: Bryostatin dose response values using flow cytometry

\begin{tabular}{lllllll}
\hline & JL & \multicolumn{3}{c}{ JH } & \multicolumn{3}{c}{ FW } \\
Conc. & \%Pos & MFI & \%Pos & MFI & \%Pos & MFI \\
\hline $0 \mathrm{nM}$ & 0.94 & 5.52 & 6.94 & 3.56 & 13.37 & 4.47 \\
$10 \mathrm{nM}$ & $1.32^{*}$ & $5.54^{*}$ & $16.11^{*}$ & $5.31^{*}$ & $12.42^{*}$ & $4.04 *$ \\
$20 \mathrm{nM}$ & 0.78 & 5.19 & 15.91 & 5.29 & 11.81 & 3.62 \\
$40 \mathrm{nM}$ & 0.61 & 5.09 & 4.02 & 2.82 & 3.2 & 1.87 \\
\hline
\end{tabular}

These were results obtained when the optimal concentration of bryostatin was determined. The B-CLL cells were from three patients; JL, JH and FW. The cells were used in the flow cytometer study, in which the cells under the influence of some stimulators, expressed SLAMF7 receptors, the presence of which was detected by fluorescence. FW could show a high level of expression even in the untreated state. This confirms the high level of expression of these receptors in untreated B-CLL cells. It also confirms the optimal concentration of Bryostatin at $10 \mathrm{nM}$. The B-CLL cells were from 3 patients, JL, JH and $F W$. 
with PMA. It thus suggests that PMA treatment caused the most increase in induction of the SLAMF7 receptor and cell clumping (Fig. 1B).

The levels of expression of SLAMF7 receptors on B-CLL cells of patients

To determine the level of SLAMF7 receptors on B-CLL cells, the cells were exposed to varied conditions: untreated, PMA and with Bryostatin. The levels of expression of positive SLAMF7 were studied and the results indicated that different B-CLL cells expressed different levels. Two (2) out of the twelve (12) cases (17\%) studied showed more than $40 \%$ positivity for SLAMF7 cells when untreated (Fig 2). More than $40 \%$ (5 out of the 12 cases) of BCLL cells studied were positive (above $10 \%$ positivity) for SLAMF7, 83\% (10 out of the 12) of these cases also showed expression level below $10 \%$ positivity.

Approximately $50 \%$ of all cases studied had two fold increases in the percentage positivity of SLAMF7 expression when the untreated cells were subsequently treated with PMA. However, cells from the 2 B-CLL cases, which had a high percentage positivity of SLAMF7 expression, did not show much increase when treated with PMA. One (1) case, representing $8 \%$ of the cases studied, showed a decrease in the level of expression after treatment with PMA. However, there was slight increase of SLAMF7 expression when the same case was subjected to Bryostatin treatment.

Similarly, 3 out of the $12(25 \%)$ studied showed a decrease in modulation with Bryostatin while 9 out of $12(75 \%)$ had elevated positive cells after modulation with Bryostatin. Whilst $75 \%(9 / 12)$ of cases showed greater increase in the level of SLAMF7 modulation with PMA than with Bryostatin, 17\% (2/12) showed higher SLAMF7 expression levels with Bryostatin than with PMA with only $1 / 12$ showing equal increase in SLAMF7 modulation with both PMA and Bryostatin drugs.

\section{Expression of SLAMF7 receptors using con- focal microscopy}

To confirm and establish the results showing high level of expression associated with B-CLL as seen in our study, we further studied the
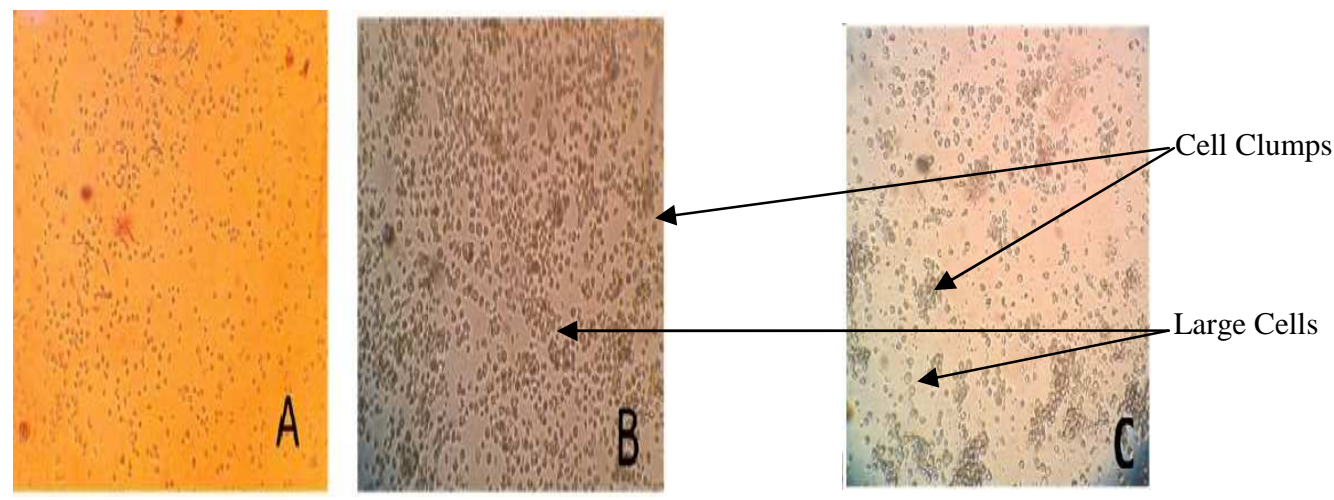

Fig. 1: Morphological changes of B-CLL cells after cell culturing when untreated and treated with PMA and bryostatin

Photomicrographs were taken with Wilovert inverted microscope fitted with Olympus camera after 24 hours of incubation. Photomicrograph A shows cells without treatment used as a negative control where cells do not adhere to each other or form clumps. Photomicrograph B shows high number of cells clustered together in clumps after treatment with PMA. Photomicrograph $C$ show moderate to high number of cells clustered together with some mild forms of clump formations after treatment with Bryostatin 


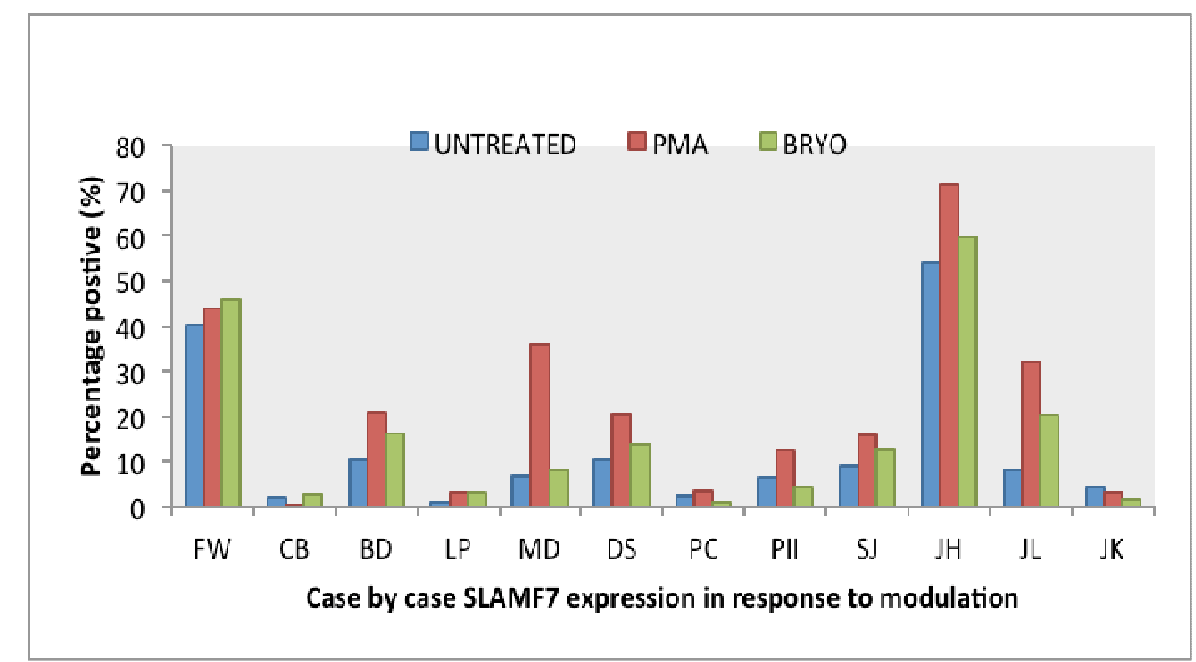

Fig. 2: SLAMF7 expressions in response to exposure to different conditions

$B$-CLL cells from different patients were exposed to different conditions (untreated, PMA, bryostatin), for the expression of $S L A M F 7$ receptors, which were measured by fluorescence in the flow cytometer. Each peak in the graph, showing percentage SLAMF7 positivity, represents a response generated from the Dako flow cytometer. $F W, C B, B D, L P, M D, D S, P C, P I I$, $S J, J H, J L$ and $J K$ are codes of B-CLL patients whose white cells were used.

level of fluorescence on selected positive and negative cases recorded from the flow cytometry results. Results obtained confirmed the high level of SLAMF7 expression on some untreated B-CLL cells. Recorded results from the light microscopy (Fig 3A) and from the confocal microscope (Fig 3B and 3C) of case $\mathrm{JH}$ showed fluorescence on the surface of the immunofluorescence stained SLAMF7 cells (Fig. 3B) whereas the control staining (irrelevant antibody) was negative (Fig. 3C). However, there were no green patches of fluorescence seen on the negative case BD. This also gave a negative result from flow Cytometry. (Fig.3E).

\section{Expression of SLAMF7 isoforms as meas- ured by RT-PCR}

To confirm the expression of two SLAMF7 isoforms in B-CLL cells, we conducted studies using RT-PCR amplification. Selected B-CLL cells without treatment were used and extracted RNA converted to cDNA. Using selected myeloma cells as controls, amplified
cDNA product from the control, showed one strong band (396 bp) and a weak band (296 bp) (Fig 4), representing two isoforms associated with myeloma cells (OMLS and MMLS). The test results of B-CLL cells showed two less intense bands, confirming the presence of low levels of SLAMF7 isoforms in B-CLL cells.

\section{DISCUSSION}

The study observed that the optimal dose for upregulating B-CLL cells was $10 \mathrm{nM}$ (table 1). This is in agreement with previous observation by Drexler et al. (1989) who reported the same concentration for Bryostatin for effective upregulation of SLAMF7 on B- CLL cells. Other studies have established similar concentration for phorbol esters in inducing increase in SLAMF7 receptors on the cell surface (Murphy et al., 2002).

B-CLL cells responded to treatment with PMA and Bryostatin by cellular proliferation and aggregation. This was evident as abnormal 
SLAMF7 expression levels on B-CLLL $\underline{\text { cells... }} \underline{-}_{-} 6 \underline{9}$
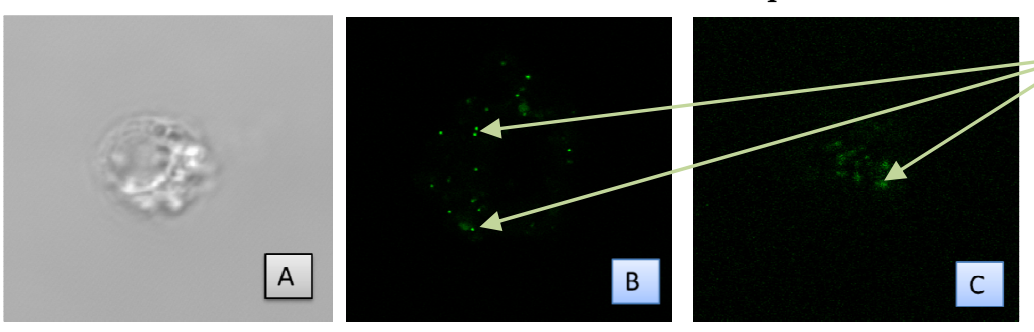

Green patches of fluorescence on B-CLL cell surface
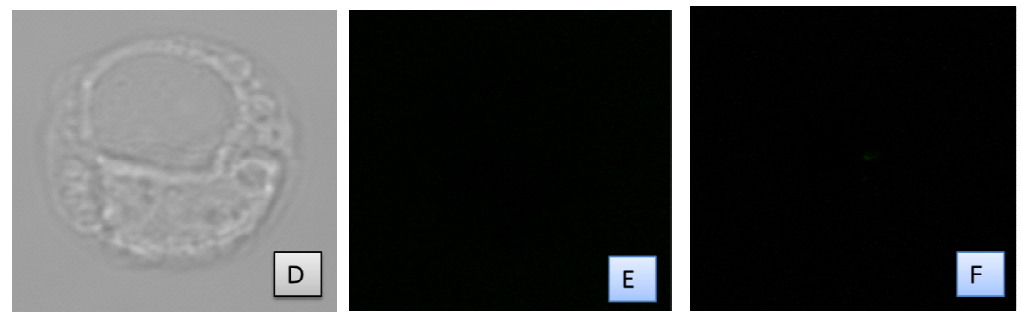

Fig. 3: Confocal microscopy showing positive and negative immunofluorescence for selected SLAMF7 B-CLL cell.

Two patients samples measured for high and low expression levels of SLAMF7 with flow cytometry were selected for observation of immunofluorescence under the confocal microscope. Pictures A, B and C represent positive SLAMF7 B-CLL cell with FIT C-labelled dye. These fluoresced with green colour under a confocal microscope as observed in $B$ and $C$ pictures and as a white patch on a black and white background as seen with picture A. Pictures E and F were negative for SLAMF7 expression on the selected B-CLL cell with FIT C-labelled dye.

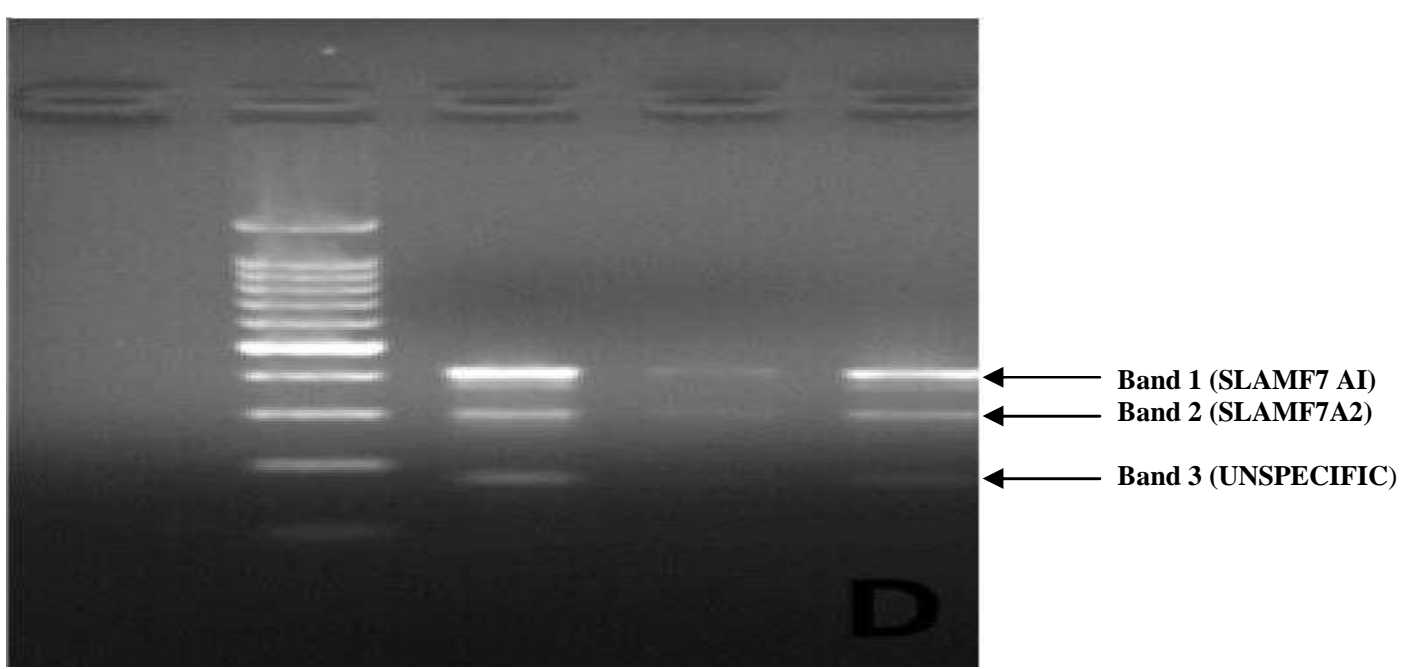

Fig. 4: Ethidium bromide-stained gels showing isoforms of SLAMF7 expression

Two multiple myeloma cell lines are shown which had positive expression of SLAMF7. The CDNA of SLAMF7 was run on agarose gel electrophoresis, using a 100kb molecular marker. Lanes 2 and 4 produced a strong and a weak band. OMLS and MMIS were the myeloma cells used as positive control; both show the two bands representing the isoforms of SLAMF7. The cell from patient $C B$ also showed two bands of equal intensity 
morphological characteristics, seen as clumps and clusters of enlarged B-CLL cells (Fig. 1). Some B-CLL cells however, did not show any any abnormal morphological characteristics. However, the lack of response of some of the other cells cannot be explained. The characteristic feature of clumped and enlarged cell is similar to observation by Springer et al., (1987) and Springer (1990) who indicated that activation of lymphocytes is coupled with the increased formation of clumps. It was evident however, that PMA induced more cellular proliferation and aggregation, hence more clumping to each other B-CLL cells than Bryostatin (Figs. 1B and 1C).

SLAMF7 receptors have been found to play an important role in the activation of B-CLL cells, thus resulting in proliferation and/or differentiation of these cells (Cambier et al., 1994; Jiang et al., 2005). In our study, SLAMF7 receptors showed varying levels of expression on BCLL cells using immunofluorescence, flow cytometry and confocal microscopy, which is in agreement with observations by Williams et al. (2004) and Williams et al. (2013). This result is however, contrary to what had been previously suggested, that all B-CLL cells express low levels (below $10 \%$ positivity) of SLAMF7 or show complete absence of SLAMF7 expression (Hsi et al., 2008).

When B-CLL cells were treated with PMA in vitro, the cells were shown to portray varied characteristics, from the change in shape, size, extensions and cell numbers when stimulated by PKC activators (Drexler et al., 1989) in the signal transduction pathway. Our study showed $83 \%$ (10 out of the 12 cases) responding positively to PMA treatment, compared with $75 \%$ ( 9 out of the 12 cases) of B-CLL cases that responded to Bryostatin treatment (Fig 2). This is in conformity with observation by Drexler $e t$ al. (1989), and Garcia et al.(2006). More than $50 \%$ of cases however showed different levels of positivity for SLAMF7 expression before treatment with PMA or Bryostatin.
This study as shown in Fig 4, found two isoforms of SLAM receptors, namely SLAMF7 and SLAMF7A2, on the B-CLL cells which are associated with multiple myeloma cells. An observation by Murphy et al. (2002) suggests that SLAMF7 is an active form of the two isoforms, which is targeted by Elotuzumab in the current treatment of multiple myeloma. We therefore suggest that the SLAMF7 isoform identified in our study might be a possible target by Elotuzumab for the treatment of CLL patients. Our study found over $50 \%$ positivity of SLAMF7 expression in the B-CLL cases studied.

While extensive studies have been done with PMA, Bryostatins represent a newer discovery and provides the advantage of being antipromoters (Ueno et al., 2012). Differences in the extent and effect of the two PKC activators (PMA and Bryostatin) have been reported (Wender et al., 1988; Kedei et al., 2013a; Kedei et al., 2013b). In contrast to PMA, Bryostatins do not have tumour promoting activity, but rather show anti-neoplastic features (Hennings et al., 1987; Nakagawa et al., 2009). In this study, $10 \mathrm{nM}$ of bryostatin provided an effective concentration at which, activation of the B-CLL cells and SLAMF7 are optimal where $75 \%$ of all cases of B-CLL cells studied had increase in SLAMF7 receptors with bryostatin modulation (Drexler et al., 1989). However, beyond this concentration, the SLAMF7 receptors did not increase any further, suggesting that increasing bryostatin beyond $10 \mathrm{nM}$ might not increase the expression of receptors any more. The reason for this phenomenon cannot be explained and might require further investigation.

The two identified isoforms of the SLAMF7 (SLAMF7 and SLAMF7 A2) genes in this study (Fig 4), as have also been previously reported by Murphy et al., (2002), were considered to be involved in the signal transduction pathway, with SLAMF7 noted as the active isoform. Not much information is known on the role of SLAMF7A2 in the immune cell. The 
RT-PCR study showed the presence of SLAMF7 and SLAMF7A2 in myeloma cells, (OMLS and MM1S), and also in the B-CLL cells (CB) (Fig 4). However, it is noted that the relative levels of expression of SLAMF7 are much higher in myeloma cells, compared to BCLL cells (Fig 4). Also in myeloma cells, the relative intensity of band 1 (SLAMF7) is higher than band 2 (SLAMF7A2), whereas in the BCLL cell, the two bands show equal intensity. These results were consistent with the findings of Murphy et al. (2002) and $\mathrm{Ju}$ et al. (2012) who also observed two equal bands (isoforms) with SLAMF7.

\section{CONCLUSION}

The study has demonstrated that SLAMF7 levels of expression vary with different B-CLL cells, and the majority of these cells respond to PKC activators (PMA and Bryostatin) by increase in proliferation, differentiation accounting for some changes in morphological characteristics.

Currently, Elotuzumab, a monoclonal antibody has been used to target high SLAMF7 expressing receptors in cells like myeloma cells. Our study has shown the high expression of SLAMF7 receptors on some B-CLL cells, implying that without treatment with PKC activators, Elotuzumab could be used to treat some B -CLL cells. This could provide a novel treatment for CLL patients.

Our study confirmed possible upregulation of the SLAMF7 receptors on B-CLL cells with PKC activators like PMA and Bryostatin. This could therefore lead to possible successful treatment of CLL patients who express low levels of SLAMF7 receptors. The study further confirms the presence of two isoforms of SLAMF7.

\section{RECOMMENDATION}

The study could not measure the level of SLAMF7 expression levels after modulation. It is recommended that further studies be undertaken to investigate the expression levels of
SLAMF7 gene after treatment with the PKC activators to determine the effect of this treatment on the levels of expression of the isoforms.

\section{REFERENCES}

Bouchon, A., Cella, M., Grierson, H. L., Cohen, J. I. and Colonna, M. (2001). Cutting edge: activation of NK cell-mediated cytotoxicity by a SAP-independent receptor of the CD2 family. The Journal of Immunology 167 (10): 5517-5521.

Calpe, S., Wang, N., Romero, X., Berger, S. B., Lanyi, A., Engel, P. and Terhorst, C. (2008). The SLAM and SAP gene families control innate and adaptive immune responses. $\mathrm{Ad}$ vances in Immunology, 97; 177-250.

Cambier, J. C., Pleiman, C. M. and Clark, M. R. (1994). Signal transduction by the B cell antigen receptor and its coreceptors. Annual Review of Immunology, 12 (1): 457-486.

Cambier, J. C. and Ransom, J. T. (1987). Molecular mechanisms of transmembrane signaling in B lymphocytes. Annual Review of Immunology, 5 (1): 175-199.

Drexler, H. G., Gignac, S. M., Jones, R. A., Scott, C. S., Pettit, G. R., Hoffbrand, A. V. (1989). Bryostatin 1 induces differentiation of B-chronic lymphocytic leukemia cells. Blood. 74 (5): 1747-1757.

Garcia, C. S., Curiel, R. E., Mwatibo, J. M., Pestka, S., Li, H. and Espinoza-Delgado, I. (2006). The antineoplastic agent Bryostatin-1 differentially regulates IFN- $\gamma$ receptor subunits in monocytic cells: transcriptional and posttranscriptional control of IFN- $\gamma \mathrm{R} 2$. The Journal of Immunology, 177 (4): 2707-2716.

Hennings, H., Blumberg, P. M., Pettit, G. R., Herald, C. L., Shores, R. and Yuspa, S. H. (1987). Bryostatin 1, an activator of protein kinase $\mathrm{C}$, inhibits tumor promotion by phorbol esters in SENCAR mouse skin. Carcino 
Genesis, 8 (9): 1343-1346.

Hennings, H., Victor, A. R., Delores, M. M., George, R. P., Reinhard, J. and Stuart, H. Y. (1990) Development of an in vitro analogue of initiated mouse epidermis to study tumour promoters and antipromoters. Cancer Research 50 (15): 4794-4800.

Hsi, E. D., Steinle, R., Balasa, B., Szmania, S., Draksharapu, A., Shum, B.P., Huseni, M., Powers, D., Nanisetti, A. and Zhang, Y. (2008). CS1, a potential new therapeutic antibody target for the treatment of multiple myeloma. Clinical Cancer Research, 14 (9): 2775-2784.

Hugo Gene Nomenclature, HGNC/Gene families/ grouping nomenclature. [online] $\mathrm{Na}$ tional Human Genome Research Institute (NHGRI) grant and Wellcome Trust grant. Available from: <http://www.genenames.org/ $>$ [Accessed 2/8 2013].

Isakov, N., Scholz, W. and Altman, A. (1986). Signal transduction and intracellular events in T-lymphocyte activation. Immunology Today, 7 (9): 271-277.

Jiang, X., Zhang, Y., Liu, B., Zhang, S., Wu, Y., Yu, X. and Mao, N. (2005). Human mesenchymal stem cells inhibit differentiation and function of monocyte-derived dendritic cells. Blood, 105 (10): 4120-4126.

Ju, Z., Wang, C., Li, Q., Hou, M., Gao, S., Hou, Q., Li, J., Huang, J. and Zhong, J. (2012). Alternative splicing and mRNA expression analysis of bovine SLAMF7 gene in healthy and mastitis mammary tissues. Molecular Biology Reports, 39 (4): 4155-4161.

Kedei, N., Telek, A., Michalowski, A. M., Kraft, M. B., Li, W., Poudel, Y. B. and Blumberg, P. M. (2013a). Comparison of transcriptional response to phorbol ester, bryostatin 1, and bryostatin analogs in LNCaP and U937 cancer cell lines provides insight into their differential mechanism of action. Biochemical Pharmacology, 85(3): 313-324.

Kedei, N., Lewin, N. E., Géczy, T., Selezneva, J., Braun, D. C., Chen, J. and Herrmann, M. A. (2013b) Biological profile of the less lipophilic and synthetically more accessible bryostatin 7 closely resembles that of bryostatin 1. ACS Chemical Biology, 8 (4): 767-777.

King, S. L. (1988). An assessment of phosphoinositide hydrolysis in antigenic signal transduction in lymphocytes. Immunology, 65 (1); 1 .

Lee, J. K., Mathew, S. O., Vaidya, S.V., Kumaresan, P.R. and Mathew, P.A. (2007). CS1 (CRACC, CD319) induces proliferation and autocrine cytokine expression on human $\mathrm{B}$ lymphocytes. The Journal of Immunology, 179 (7): 4672-4678.

Muhie, S., Hammamieh, R., Cummings, C., Yang, D. and Jett, M. (2013). Transcriptome characterization of immune suppression from battlefield-like stress. Genes and Immunity, 14(1): 19-34.

Murphy, J. J., Hobby, P., Vilarino-Varela, J., Bishop, B., Iordanidou, P., Sutton, B. J. and Norton, J. D. (2002). A novel immunoglobulin super family receptor (19A) related to CD2 is expressed on activated lymphocytes and promotes homotypic B-cell adhesion. Biochemical Journal, 361 (3): 431-436.

Nakagawa, Y., Yanagita, R. C., Hamada, N., Murakami, A., Takahashi, H., Saito, N., Nagai, H. and Irie, K. (2009). A simple analogue of tumor-promoting aplysiatoxin is an antineoplastic agent rather than a tumor promoter: development of a synthetically accessible protein kinase $\mathrm{C}$ activator with Bryostatin-like activity. Journal of the American Chemical Society, 131 (22): 7573-7579.

Nishimoto, T., Kashiwagi, K., Saito, N. and 
Shirai, Y. (2013). Both C1B domain and pseudosubstrate region are necessary for saturated fatty acid-induced translocation of \&PKC to the plasma membrane: Distinct role of intramolecular domains for different translocation. Biochemical and Biophysical Research Communications, 432(2): 384-388.

Richardson, P. G., Paul, G., Sagar, L., Andrzej, J., Jakubowiak, J. H. and Kenneth, C. A. (2011). Monoclonal antibodies in the treatment of multiple myeloma. British Journal of Haematology, 154 (6): 745-754.

Springer, T. A. (1990). Adhesion Receptors of the Immune System. Nature, 346 (6283): 425 -434 .

Springer, T. A., Michael L. D., Takashi K. K., and Steven, D. M. (1987). The lymphocyte function associated LFA-1, CD2, and LFA-3 molecules: cell adhesion receptors of the immune system. Annual Review of Immunology, 5 (1): 223-252.

Stark, S. and Watzl, C. (2006). 2B4 (CD244), NTB-A and CRACC (CS1) stimulate cytotoxicity but no proliferation in human NK. cells. International Immunology, 18 (2): 241-
247

Ueno, S., Yanagita, R. C., Murakami, K., Murakami, A., Tokuda, H., Suzuki, N. and Irie, K. (2012). Identification and biological activities of bryostatins from Japanese Bryozoan. Bioscience, Biotechnology and Biochemistry, 76 (5): 1041-1043.

Veillette, A. and Latour, S.(2003). The SLAM family of immune-cell receptors. Current Opinion in Immunology, 15 (3): 277-285.

Wender, P. A., Cribbs, C. M., Koehler, K. F., Sharkey, N. A., Herald, C.L., Kamano, Y., Pettit, G. R. and Blumberg, P.M. (1988). Modeling of the Bryostatins to the phorbol ester pharmacophore on protein kinase C. Proceedings of the National Academy of Sciences, 85 (19): 7197-7201.

Williams, M., Tso, J. Y., Landolfi, N. F. and Liu, G. (2013). U.S. Patent No. 8,445,646. Washington, DC: U.S. Patent and Trademark Office.

Williams, M., Landolfi, N. F., Liu, G., Powers, D. B. and Tso, J. Y. (2004). U.S. Patent Application $13 / 175,748$. 